\section{¿Sociedad Anónima de Responsabilidad Social? ¡SE NECESITA URGENTE UN CORAZÓN \\ PARA LAS EMPRESAS!}

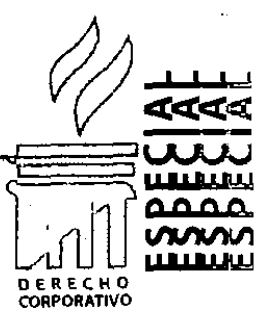

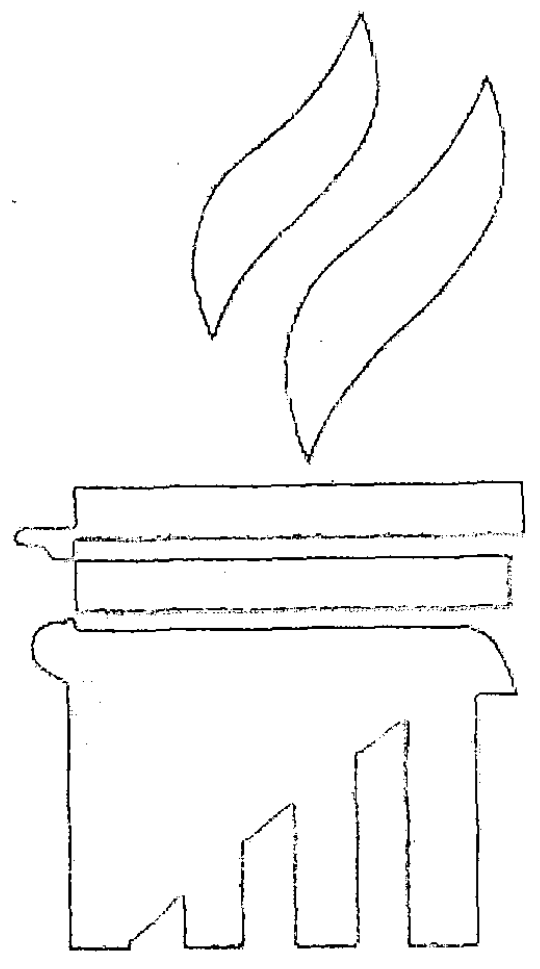

Edgardo Mercado Neumann

Abogado por la Pontificia Universidad Católica del Perú.

Profesor del curso Asociaciones Público-Privadas en la

Pontificia Universidad Católica del Perú.

Miembro del proyecto para la creación de una nueva generación de codificación civil y comercial de la Asociación Latinoamericana y del Caribe de Derecho y Economía (ALACDE).

Miembro del Instituto Peruano de Derecho Mercantil. Miembro

Adherente de la "Asociación Argentina de Derecho Administrativo".

Miembro Titular del "Instituto de Derecho Administrativo" de la Universidad Notarial de Argentina.

Profesor Principal en la Academia de la Magistratura.

\section{Miguel Ángel león Untiveros}

Abogado por la Pontificia Universidad Católica del Perú. Master of Business Administration - MBA por la Maastricht School of Management, Holanda.

Profesor de Derecho Mercantil en la Pontificia Universidad

Católica del Perú y Profesor de Planeamiento

Estratégico en la Universidad Inca Garcilaso De La Vega.

Presidente del Centro de Investigación de la Asociaciones Público-Privadas - CIAPP.

SUMARIO:

I. Introducción.

II. El Surgimiento de las sociedades y su problemática en el siglo XXI.

III. La empresa, la sociedad y la persona jurídica.

IV. Hacia una nueva concepción de empresa: El realismo sistémico.

V. El objeto social, el "Proyecto de Vida" y la visión y misión de la empresa.

VI. El mercado y el nuevo rol del consumidor $y$ usuario.

VII. La persona jurídica y el concepto de lucro.

VIII. El fundamento de la responsabilidad juridica de las personas jurídicas.

IX. El origen de la responsabilidad social de las personas jurídicas.

$X$. ¿Qué es responsabilidad social?

XI. De los "Shareholders" a los "Stakeholders".

XII. Inclusión empresarial y cultura corporativa.

XIII. Las asociaciones público-privadas y el desarrollo de políticas públicas de responsabilidad social.

XIV. Conclusión: La necesidad de crear una sociedad anónima de responsabilidad social. 


\section{INTRODUCCIÓN}

En el presente trabajo, los autores proponen una nueva forma societaria: la sociedad anónima de responsabilidad social. Para ello, se hace un recorrido desde el surgimiento de la sociedad anónima, analizando los factores históricos y económicos que le dieron origen, así como aquellos que la justifican hoy en día.

No se trata en ningún caso de cuestionar la vigencia de la sociedad anónima, sino de justificar la evolución de la misma hacia nuevas modalidades, que satisfagan intereses modernos sin alterar la esencia de la institución. Es importante recalcar que la nueva forma societaria que proponemos no sustituye ni altera las existentes, en todo caso se suma a ellas abriendo el abanico de elección. Para ello, sin embargo, es necesario destruir algunos mitos y romper moldes, evaluar en esta evolución histórica, desde el buen gobierno corporativo hasta la responsabilidad social, sumado los aportes de la concepción de la sociedad anónima que brinda el realismo sistémico y que permite concebirla en su actual entorno.

Finalmente, se analiza este nuevo esquema legal con especial referencia a las asociaciones público-privadas, lugar en el que se muestra la enorme importancia y utilidad del mismo.

\section{EL SURGIMIENTO DE LAS SOCIEDADES Y SU PROBLEMÁTICA EN EL SIGLO XXI}

Hace dos siglos, los juristas más renombrados se involucraron en una aventura que revolucionaría el mundo y la manera de vivir de todos sus habitantes. No se trataba de una aventura nueva ni de un esfuerzo sin precedentes, pues ya antes la ciencia y la literatura habían intentado o imaginado en vano, lo que los juristas de entonces lograron con éxito: crear un ser o un ente a imagen y semejanza del hombre, con la idea de permitir la realización de los intereses predominantes del momento y satisfacer mu- chas de nuestras más importantes necesidades. A esta creación se le denominó "persona jurídica", como para que quedaran en claro dos cosas: (i) que si bien era una "nueva entidad" creada a imagen y semejanza del hombre, no era un verdadero ser humano (a estos últimos, en adelante, se le llamaría personas naturales); y, (ii) que la nueva entidad había sido inventada por los juristas como respuesta del derecho a las exigencias de las empresas de entonces, sustentados en razones económicas y de mercado.

Han pasado más de dos siglos y esta "persona" creada por los juristas, ha crecido, se ha desarrollado y ha poblado el mundo, al extremo que hoy se ha convertido en la especie dominante del planeta. En un príncipio, los seguidores de una teoría afirmaban que la única persona real es el ser humano, ergo las otras solo podian ser una ficción legal, pero esto no hizo sino avivar una discusión teórica entre ellas. La respuesta de la teoría de la realidad defendida por Gierke y sus seguidores llegó a afirmar que estos entes son "realidades vivas" en la medida que, como los humanos, tienen potestad propia y son sujetos de derechos. En el otro extremo, la concepción formalista, sostenida por Regelsberger, Kelsen, Von Thur, entre otros, señala que la personalidad jurídica es "la personalización de una parte del ordenamiento jurídico".

No son estas posturas las únicas que han querido explicar el fenómeno de la sociedad anónima cono sujeto de derecho, ni es nuestra intención tratar las diferentes teorías que lo han intentado, incluso con mayor éxito. ${ }^{1}$ Sin embargo han de tenerse en cuenta a efectos de entender cómo a lo largo de la existencia de esta creación jurídica, no han faltado los que han oscilado entre considerarlas una ficción, como los que la han concebido como una realidad viviente.

Pero sea cual fuera la teoría de nuestra preferencia, es un hecho indiscutible que estas personas jurídicas son una institución de gran importancia y que han merecido el reconoci-

1 DE CASTRO Y BRAVO, Federico, La Persona Juridica, Civitas, Madrid, 1991, p. 21 y ss. 
miento y la protección de los ordenamientos jurídicos del mundo. Así, reciben el tratamiento de verdaderos sujetos de derecho, como los humanos, a los que se asemejan porque tienen un "sistema orgánico" que les permite formar su propia voluntad y tomar libremente decisiones, como el ser humano tiene un cerebro; se les da un nombre (denominación o razón social) desde que nacen, el mismo que figura en su partida de nacimiento en registros públicos, quien les asigna a cada una, una partida electrónica. Asimismo, se les dota de un registro único de contribuyente que es una suerte de documento de identidad. Tienen un domicilio pero pueden mudarse. De alguna manera, se les permite tener "familia" como ocurre con las filiales y sucursales o incluso con los Grupos de empresas. Gozan de un patrimonio propio, el que destinan a una serie de actividades económicas según los fines que persigan, que van desde los lucrativos hasta los de solidaridad y beneficencia. También se les reconoce una suerte de derecho al honor y a la intimidad. Finalmente mueren, liquidándose su patrimonio como en las sucesiones y extinguiéndose, momento en que se extiende la correspondiente partida de defunción, en la misma partida electrónica en la que como en nuestros álbumes y diarios, quedan registradas sus vidas y su paso por este mundo.

En consecuencia, a pesar de que las discusiones jurídicas no han cesado o recalado en una explicación única del fenómeno, la persona jurídica es innegablemente parte de nuestra realidad jurídica, económica, política y social. Pero la realidad que dio origen a la creación de la persona jurídica es distinta a la actual, como son diferentes las ideas predominantes que explican el mundo actual y sus necesidades. Algunas de estas ideas y necesidades exigen al jurista actual revisar su creación, dotar a las sociedades de mecanismos que le permitan una mejor conciencia de su entorno y de una mayor sensibilidad frente a las necesidades del mundo en que vivimos. Por qué no decirlo, las sociedades necesitan urgentemente un implante de corazón.

Por ejemplo, hace algunos años se empezó a cuestionar a nivel mundial la importancia ética del buen gobierno, cobrando gran difusión el concepto del buen gobierno corporativo. ${ }^{2} \mathrm{Es}$ así que ante casos como el ocurrido en el 2001, en el que se descubrió uno de los fraudes más grandes de la historia debido al mal manejo y desleal información de los altos ejecutivos de la empresa Enron, hubo que replantear y profundizar los lineamientos de conducta de los directivos de las empresas en caso de conflicto de intereses. ${ }^{3}$

De otro lado, somos testigos de la mayor importancia que cobra cada día el fenómeno de la responsabilidad social, el mismo que se entiende como"la capacidad de respuesta que tiene una empresa o una entidad, frente a los efectos e implicaciones de sus acciones sobre los diferentes grupos con los que se relaciona (stakeholders o grupos de interés). De esta forma las empresas son socialmente responsables cuando las actividades que realiza se orientan a la satisfacción de las necesidades y expectativas de sus miembros, de la sociedad y de quienes se benefician de su actividad comercial, así como también, al cuidado y preservación del entorno".

En tercer lugar, nos llega desde otras disciplinas conceptos sobre la exclusión/inclusión social que parten de la marginalidad y la pobreza para construir caminos o políticas de desarrollo sostenible y que hoy son teorías universales que tratan de explicar los problemas sociales para implementar políticas de desarrollo sostenible, que permitan el acceso igualitario a los bienes básicos y servicios, la no discriminación en los mercados de trabajo y protección social,

2 Se entiende por buen gobierno corporativo: "la transparencia con los accionistas, los clientes, los empleados y la sociedad".

3 Desde un punto de vista económico el conflicto de intereses puede plantearse como los costos de agencia entre el agente y el principal, siendo que la solución debe ser aquella que determine los incentivos eficientes que logre alinear los intereses del agente con los del principal. 
y otorguen garantías de participación ciudadana efectiva y revalorización del sujeto a la luz de la comprensión de realidades sociales como el género, etnia, características físicas o discapacidad, identidad sexual y religión, por citar las principales. Como no podía ser de otra manera, estas teorías vienen iluminando también la disciplina jurídica en todos sus extremos, incluyendo instituciones tan básicas como las formas societarias.

Podemos decir entonces que los juristas, al crear personas jurídicas olvidaron quizás lo más importante, el corazón, los sentimientos y en especial la conciencia: y en esta omisión permitieron que estas personas jurídicas causaran sin frenos morales ni remordimientos, todo tipo de daños, al planeta, a otras personas jurídicas y lo que es peor, al hombre. Doscientos años después, diferentes movimientos surgen desde la sociedad para corregir esta tremenda omisión y buscar la forma de crearles un corazón. Este movimiento proviene principalmente de dos fuentes: la primera de la llamada "responsabilidad social", la segunda del concepto de "inclusión" aplicado al derecho. Veamos brevemente cada uno de ellos, sin perjuicio de explicarlos luego con mayor detenimiento.

De la mano con esta responsabilidad se desarrollan en la noción de empresa, conceptos novedosos traídos de otros campos como la psicología y la administración. Ahora se habla de identidad corporativa (conjunto de símbolos y distinciones que una entidad utiliza para distinguirse de las demás). La identidad corporativa, a su vez, está compuesta por cuatro atributos: el comportamiento corporativo constituido por el patrón de conducta común de los individuos y grupos que integran una organización; la cultura corporativa, que es la más difundida y que está conformada por la filosofía y los valores básicos que rigen en una organización, en forma tal que orientan la política de la empresa con respecto a clientes, socios, empleados, proveedores, organismos, la comunidad local y en general con todos aquellos afectados directa o indirectamente por ella (los stakeholders); la imagen visual compuesta por todos los signos gráficos externos, logotipos, colores, etc., que tienen por objeto definir ante todos los públicos una imagen definida; y, la comunicación corporativa compuesta por todas las actividades, acciones y formas de expresión de una empresa o institución que transmiten y difunden en su entorno su cultura corporativa.

La expresión cultura corporativa, por ejemplo, tiene sus orígenes en la década de los setenta, dentro del ámbito empresarial, cuando las escuelas de negocios consideraron ilustrativo extrapolar los mecanismos del comportamiento del ser humano al ámbito de la empresa. De la misma manera como el comportamiento del ser humano nos permite conocerlo y distinguirlo de otro, el comportamiento de la empresa nos permite identificarla, reconocerla y distinguirla de las demás.

La segunda vertiente viene de la educación y la economía, específicamente del modelo económico que considera que no puede haber desarrollo sin inclusión de los más pobres, de los marginados, de los discapacitados, de los menos preparados y por ende intenta imponer fórmulas modernas y aceptables de desarrollo sostenible como las asociaciones público-privadas. Según este modelo, la empresa privada y la sociedad civil organizada deben asumir un rol protagónico en la economía y el desarrollo económico sostenible, aportando sus recursos económicos, humanos y tecnológicos en las obras de infraestructura y los servicios públicos que un país necesita. El Estado por su parte, asume un rol subsidiario, promotor de la inversión y de árbitro del mercado. A diferencia de la responsabilidad social, el Derecho ha recogido este modelo partiendo de la Constitución y ha sido desarrollado eficientemente a nivel de Gobierno Central. Falta extender con eficiencia este modelo a nivel de Gobiernos Regionales y Locales y quizás el modelo en sí, deba sufrir serias modificaciones y adaptaciones, pero lo que interesa es que existe y ha sido recogido e implementado por el legislador y el gobierno peruano.

En este nuevo rol, la cerebral, fría y calculadora persona jurídica, que solo piensa en el lucro y en sus intereses o los de sus accionistas requiere 
urgentemente de cirugía jurídica que permita implantarles un corazón, que pueda latir al ritmo del Interés Público y Social y sea el socio ideal que busca el Estado con las Asociaciones Público- Privadas.

\section{LA EMPRESA, LA SOCIEDAD Y LA PERSONA JURÍDICA}

De lo anterior surge la siguiente cuestión: ¿puede la persona jurídica cumplir el rol social y de inclusión que se le reclama? Para responder a esta pregunta, reevaluemos los conceptos de empresa, sociedad y persona jurídica.

Para los economistas, la empresa es una "entidad creada por los individuos para algún propósito. Esta entidad típicamente adquirirá inputs y los combinará para obtener outputs. Los inputs son adquiridos en los mercados, y esto constituye los costos de la empresa. El output es vendido en el mercado, y la firma obtiene una ganancia por ello".4

Por su parte la sociedad es la manifestación de la libre iniciativa privada y de la libertad de asociación. Tiene una doble naturaleza jurídica, pues así como se señala que la sociedad es una persona jurídica, también se afirma que es un contrato ${ }^{5}$. Asimismo, la sociedad (en especial, la sociedad anónima) tiene dos características que queremos resaltar ${ }^{6}$ : el principio de la finalidad lucrativa y el principio de la irresponsabilidad de los accionistas por las obligaciones de la sociedad frente a terceros. ${ }^{7}$

En cuanto a la persona jurídica, siguiendo a Hans Kelsen, encontramos que en efecto es el centro de imputación de normas, es decir, "la unidad personificada de un conjunto de tales normas". ${ }^{8}$ Esta definición sigue vigente. Se trata de una concepción, si se quiere, formal de la persona jurídica con prescindencia de cualquier elemento real. Cabe resaltar que existe una gran aproximación con la teoría de la ficción, que en palabras de Windscheid señalaba: "La persona jurídica no es una persona existente en realidad, sino solamente imaginaria, que es considerada como sujeto de derechos y obligaciones". ${ }^{9}$

Hoy resulta interesante la relación entre empresa y sociedad anónima, pues en la práctica se encuentran empresas que están estructuradas juridicamente como un conjunto de sociedades. Es decir, como un fenómeno por el que "a cada sociedad anónima no siempre corresponde una empresa distinta, sino que corresponde, en muchas ocasiones, únicamente un fragmento de empresa". ${ }^{10} \mathrm{El}$ empleo de esta práctica comercial potencia enormemente los beneficios de la limitación de responsabilidad a favor de los empresarios, puesto que con ello se logra disminuir el riesgo propio de la empresa, trasladándolo a la sociedad (acreedores, proveedores, auxiliares, dependientes, consumidores, entre o otros).

4 JEHLE, Geoffrey y RENY, Philip J, Advanced Microeconomic Theory, Addison Wesley, Boston, 2001, p. 117.

5 GALGANO, Francesco, Le società in genere. Le società di persone, Giuffrè, Milano, 1982, p. 3 y ss.

6 ALPA, Guido, Principi generali, Giuffrè, Milano, 1993, pp. 417 y 418.

7 Para GARRIDO DE PALMA y SANCHEZ GONZALES, el principio de la irresponsabilidad de los accionistas por las deudas sociales es un principio esencial de la sociedad anónima (ver: GARRIDO DE PALMA, Víctor Manuel y SÁNCHEZ GONZÁLES, José Carlos, La Sociedad Anónima en sus principios configuradores. En: Estudios sobre la Sociedad Anónima, Tomo I. Dirigido por MANUEL GARRIDO DE PALMA, Victor, Civitas, Madrid, 1991, p. 67 y s5.

8 KELSEN, Hans, Teoría General del Derecho y del Estado, UNAM, México, 1995, p. 110.

9 WINDSCHEID, Bernardo, Diritto delle pandette, Volume Primo, Parte Prima, Unione Tipografico-Editrice, Milano, 1902.

10 GALGANO, Francesco, Las instituciones de la economia capitalista. Sociedad anónima, Estado y clases sociales, Ariel, Barcelona, 1990, p. 90. 
Sin embargo, el análisis de la relación entre empresa y sociedad, también tiene matices sociales y económicos. Así Francesco Galgano señala: "Para comprender plenamente este efecto traslaticio del riesgo de empresa, producto de la responsabilidad limitada, es necesario tener en cuenta que los acreedores de la sociedad no se encuentran todos sobre un mismo plano: el efecto traslaticio se verifica sólo en perjuicio de los acreedores económicamente más débiles, de los pequeños proveedores, de la masa de trabajadores dependientes, de los empresarios auxiliares o satélites, como los agentes, los concesionarios, los comisionistas, etc. Los acreedores económicamente más fuertes están, en cambio, en condiciones de exigir, cuando conceden crédito a la sociedad, formas suplementarias de garantía, y, en particular, exigir la garantía real o personal de uno o más socios: la eventual insolvencia de la sociedad no les afectará, ya que podrán siempre contar con la responsabilidad ilimitada, a título de fianza, de uno o varios socios, o bien podrán afectar la hipoteca concedida, sobre los propios bienes, por uno o varios socios"."

Con respecto a la relación sociedad anónima y persona jurídica una parte de la doctrina ha calificado a la sociedad anónima de artificio cuya finalidad es únicamente eximir al verdadero dueño de la empresa de la responsabilidad derivada de sus actos en cuento tal. Así, se señala que la sociedad ya no se funda en el iusnaturalismo puesto que sirve "para despojar y esclavizar a los económicamente más débiles". ${ }^{2}$
El análisis económico del derecho señala que la limitación de la responsabilidad cumple una función importante en cuanto a la producción de beneficios sociales. ${ }^{13}$ Veamos. Uno de los problemas más importantes que afronta las empresas es el financiamiento. En el supuesto que la empresa no esté constituida como una sociedad, entonces, el empresario no tendría el incentivo de acometer los proyectos empresariales debido a que la responsabilidad ilimitada haria que asuma un riesgo muy grande. Así, la irresponsabilidad por las deudas sociales cumple un rol incentivador de producir bienes que no podrían ser elaborados fuera de la empresa. ${ }^{14}$

Siguiendo con esta línea teórica, el análisis económico del derecho señala a diferencia del planteamiento doctrinario antes visto, que la irresponsabilidad del accionista por las deudas sociales no tiene el efecto de trasladar el riesgo a la sociedad, toda vez que los respectivos agentes económicos que contratan con la empresa negociarán una mayor tasa a cargo de la misma, lo que equilibraría ambas posiciones. ${ }^{15}$ Asimismo, esta explicación no solo se aplica a los casos en que las partes tienen igual o mayor poder de negociación que el de la empresa, sino en los casos de asimetría, ya que es el Estado quien con sus reglas sobre responsabilidad generaría por ejemplo una mayor tasa de interés a cargo de la empresa y a favor de los acreedores eventuales (trabajadores, usuarios). Sin embargo, a pesar de la pulcritud de esta teoría, debe caerse en la cuenta que la realidad da razón a la postura doctrinaria de Galgano, antes señalada.

11 GALGANO, Francesco, Op. Cit., pp. 95 y 96.

12 DE CASTRO Y BRAVO, Federico, Op. Cit., p. 33.

13 POSNER, Richard A, El análisis económico del derecho, Fondo de Cultura Económica, México, 1998, pp. $372-376$.

14 Esto último cobra una mayor importancia si se tiene en cuenta que la producción de los bienes y servicios dentro de una empresa tiene un menor costo en comparación a que si se hace fuera de ella.

15 POSNER señaia que cuando una empresa toma un financiamiento, se dan dos escenarios: (i) Cuando no hay irresponsabilidad del accionista, el costo del financiamiento es menor, por ejemplo, $6 \%$, el mismo que se determinaría sobre la probabilidad del no pago de la deuda y el hecho que ante tal evento los accionistas comprometen su riqueza personal; (ii) Cuando hay irresponsabilidad del accionista, el riesgo del financista aumenta, y por ende convendrá una mayor tasa de interés de tal manera que se compense el incremento del riesgo. (POSNER, Richard A., Op. Cit., p. 374). 
Volviendo entonces a la cuestión planteada de si la persona jurídica puede cumplir el rol social y de inclusión que se le reclama, debemos responder que estando las cosas como se las ha expuesto y considerando la subsistencia de ciertos elementos perturbadores provenientes del concepto de persona jurídica y sus relaciones con las nociones predominantes de sociedad y empresa, cabe concluir que la respuesta jurídica a las cuestiones exigidas por la realidad actual antes comentadas, es insuficiente. Esto no quiere decir que deba eliminarse este concepto, habida cuenta la enorme función económica que cumple ${ }^{16}$, sino que la problemática debe replantearse en estos nuevos términos: ¿cómo puede la persona jurídica responder adecuadamente a las exigencias de la responsabilidad social y de inclusión sin alterar su esencia? En las líneas siguientes abordamos esta cuestión.

\section{HACIA UNA NUEVA CONCEPCIÓN DE EMPRESA: EL REALISMO SISTÉMICO}

A lo largo de lo señalado anteriormente, de forma implícita las diferentes posturas sobre la empresa parten de una concepción mecanicista, es decir, que se concibe a la empresa como un fenómeno sin realidad efectiva, que no transciende más allá de la realidad de los individuos que la conforman. Frente a esta concepción, existe en la actualidad la concepción holistica de la empresa, que considera que la empresa no es la mera sumatoria de sus elementos sino ha de entenderse que los mismos se encuentran en una relación recíproca que da lugar a sinergias, y logra un valor agregado que no podría explicarse desde la perspectiva mecanicista. Para Russell Ackoff, los elementos de la empresa son: (i) organización democrática, en razón de que cada elemento afecta al sistema; (ii) economia de mercado interno, donde los elementos del sistema realizan transacciones entre sí; (iii) estructura organizacionalmultidimensional: consumo interno, consumo externo y usuarios; (iv) planificación interactiva; (v) sistema de soporte de decisiones. ${ }^{17}$

Para esta concepción, la categoría conformada por los stakeholders es un elemento esencial de la empresa y hace referencia a un individuo o grupo de individuos que son directamente afectados por el desempeño de la empresa así como pueden influenciar en el futuro de la misma. ${ }^{18}$ En este marco, son plenamente justificables afirmaciones como "la mayor función social de las empresas concebidas como un sistema social es crear y proveer trabajos productivos". ${ }^{\prime 19}$

En cuanto refiere al Derecho, la sociedad anónima es real en dos sentidos ${ }^{20}$ : en primer lugar son personas juridicas al igual que los seres humanos ${ }^{21}$, y en segundo lugar, las sociedades

16 En efecto, la sociedad anónima cumple por lo menos dos funciones de gran importancia: (i) constituye un incentivo eficiente para asumir riesgos que benefician a la sociedad, y (ii) genera la reducción de los costos de producción de bienes y servicios.

17 ACKOFF, Russell L, Re-Creating the Corporation, Oxford University Press, New York, 1999, pp. 38 y 39

18 GHARAJEDAGHI, Jamshid, Systems Thinking: Managing Chaos and Complexity, Elsevier, Amsterdam, 2006, p. 271.

19 ACKOFF, Russell L, Op. Cit., p. 41.

20 CANE, Meter, Responsability in Law and Morality, Hart Publishing, Oxford, 2002, p. 149. Esta concepción de CANE tiene su base en las ideas de Gunther Teubner, en especial, su trabajo: Enterprise Corporatism: New Industrial Policy and the 'essence' of Legal Person. En: American Journal of Comparative Law No. 36, 1988, pp. 401-426.

21 CANE, Peter señala que debe tenerse en cuenta que la categoría de persona jurídica es una atribución que hace el Derecho. La personalidad juridica es un artefacto de las reglas juridicas, y no de la evolución o reproducción humana (CANE, Meter, Op. Cit., p. 147). En cuanto a la capacidad de ejercicio, los individuos no siempre están en dicha situación, ya que la ley prevé casos en que se restringe dicha capacidad, como es el caso de los criminales. Lo que, en términos de CANE, demuestra que la persona jurídica es una creación legal, ya sea que esta calidad recaiga en un individuo o en una empresa. 
son vehículos para la actividad humana, particularmente para la actividad en asociación. Así asistimos a un nuevo realismo, que podemos llamar "realismo sistémico".22 En consecuencia, teniendo en cuenta que el Derecho es un sistema social autopoiético ${ }^{23}$ compuesto por comunicaciones jurídicas, la naturaleza jurídica de la sociedad anónima no será otra que también de orden comunicativo.

Este cambio de enfoque sobre la naturaleza de la sociedad anónima permite postular un mayor acercamiento entre la realidad social y persona jurídica. En efecto, desde esta perspectiva no cabe apreciar una diferencia radical entre realidad y Derecho (i.e. persona jurídica), ya que desde el momento en que se concibe al Derecho mismo como subsistema social de comunicaciones jurídicas, las diferencias planteadas inicialmente por la doctrina de la ficción, anteriormente expuestas, no tienen lugar en este contexto.

La importancia de esta nueva concepción es que la cuestión de la responsabilidad social y de la inclusión no se verá como un inserto artificial de un elemento ajeno a la naturaleza de la persona jurídica, sino como el elemento faltante necesario que corresponde a su naturaleza misma.

\section{EL OBJETO SOCIAL, EL “PROYECTO DE VIDA"Y LA VISIÓN Y MISIÓN DE LA EMPRESA}

Para entender la analogía organicista hecha desde la teoría sistémica del Derecho, es necesario revisar los conceptos de objeto social, proyecto de vida, visión y misión.

Sobre el Objeto Social, la Ley General de Sociedades señala: "La sociedad circunscribe sus actividades a aquellos negocios u operaciones licitos cuya descripción detallada constituye su objeto social. Se entienden incluidos en el objeto social los actos relacionados con el mismo que coadyuven a la realización de sus fines, aunque no estén expresamente indicados en el pacto social o en el estatuto." Asi, el objeto social, define la serie de acciones económicas a las que la sociedad anónima se dedicará y que importan su presencia en la sociedad y la economía de un país.

Sobre el tema del proyecto de vida, siguiendo a Fernández Sessarego, podemos afirmar que "es un ingrediente de la propia constitución ontológica del ser humano. Surge como una exigencia, precisamente, en tanto el ser humano es libre, coexistencial y temporal. Como apunta SASTRE, el 'proyecto libre es fundamental, pues es mi ser'. El'proyecto de vida' encuentra necesariamente su origen en una decisión libre, la misma que tiende a su realización en el futuro, ya sea mediato o inmediato". ${ }^{24}$

Este concepto se aplica para el caso de las empresas, cuando hacemos referencia a los conceptos de visión y misión. Estos términos

22 Esta concepción de la persona jurídica parte de una especial concepción del Derecho: "El Derecho se define como un sistema social autopoiético, esto es, como una red de operaciones elementales. Los elementos básicos de este sistema son comunicaciones, no normas: el Derecho no es un sistema de normas, tal y como pretenden las teorias analíticonormativistas (...) El Derecho como sistema social autopoiético no está compuesto por normas ni por legisladores, sino por comunicaciones juridicas, definidas por la sintesis de tres selecciones de sentido: participación, información y comprensión. Dichas comunicaciones están interrelacionadas entre si en una red de comunicaciones que no produce otra cosa que comunicaciones". (TEUBNER, Gunther, El derecho como sistema autopoiético. En: El Derecho como sistema autopoiético de la Sociedad Global, TEUBNER, Gunther, Ara Editores, Lima, 2005, p. 42). Como una consecuencia de esta posición, la sociedad anónima ostenta una realidad social desde el momento que forma parte de la acción comunicativa del Derecho.

23 Es necesario tener en cuenta que el sistema autopoiético es aquel que sus sustenta así mismo, es un sistema que es autoorganizado y autoorientado. Esto no quiere decir que el sistema autopoiético sea ajeno a su entorno, por el contrario, la definición de sistema (para el enfoque sistémico) incluye el entorno.

24 FERNÁNDEZ SESSAREGO, Carlos, Deslinde conceptual entre 'daño a la persona' 'daño al proyecto de vida' y 'daño moral'. En: Responsabilidad Civil. Nuevas tendencias, unificación y reforma: Veinte años después. Dirigido por ESPINOZA ESPINOZA, Juan, Palestra, Lima, 2005, pp. 150 y 151. 
tienen una significación precisa en las ciencias administrativas, a saber: "La declaración de la misión contesta la pregunta '¿Cuál es nuestro negocio?' mientras que la de la visión contesta a: ¿Qué queremos ser?".25 "La visión estratégica de una empresa puede ser descrita como el concepto de un nuevo y deseable futuro que sea factible de realizar y que puede ser comunicado a toda la organización. La respuesta de la organización debe priorizar sus recurso para lograr la visión". ${ }^{26}$

Es fácil reconocer, aun cuando sea prima facie, la similitud entre el ser humano y la empresa, lo que resulta natural ya que la vida del individuo de desenvuelve en sociedad por antonomasia.

En consecuencia, existen elementos en la empresa que la dotan de una constitución propia (misión, visión), lo que hace que se la conciba más allá de sus elementos dándole a su vez una dirección (a manera de destino y vocación) y por ende contar con "un proyecto de vida" como todo ser humano.

\section{EL MERCADO Y EL NUEVO ROL DEL CONSUMIDOR Y USUARIO}

Pero no solo estamos ante cambios en la concepción de la empresa y la persona jurídica, sino que también el consumidor ha mostrado una interesante evolución. Desde la perspectiva sistémica de la empresa, el consumidor y el usuario forman parte del sistema socio-corporativo de la misma. Ellos demandarán que los bienes y servicios se produzcan al menor costo posible. Sin embargo, no se crea que es lo único que aprecia el consumidor. También le son importantes la confiabilidad, la producción responsable y otros beneficios que la empresa pueda proveer. Asimismo, algunos consumidores pueden sentirse los servicios puesto que se ignoran sus necesidades especiales habida cuenta que no caen en las categorías de un servicio convencional. ${ }^{27}$ Pero cada día adquiere mayor importancia el consumo socialmente responsable, donde marcas, sellos, patrones o programas como los expuestos anteriormente constituyen información cada vez más relevante y exigida en el mercado por los consumidores que desean tomar una decisión bien informada.

En esta línea, María Matilde Schwalb y Oscar Malca ${ }^{28}$ analizan las exigencias, normas y certificaciones aparecidas en los mercados que indican el surgimiento de nuevos parámetros que afectan los mismos, exigencias y normas impulsadas desde el mercado internacional que se han convertido en verdaderas "condiciones de acceso" a los mercados, sustentadas en "un cambio en las costumbres de consumo de la sociedad que demandan de las empresas el compromiso de ser responsables tanto en lo ambiental como en lo social, a través de prácticas laborales más justas y de controlar su impacto en la sociedad en general".

Estas exigencias y certificaciones resultan relevantes desde la perspectiva de la asimetría informativa que afecta al consumidor. Un consumidor razonable debe estar adecuadamente informado respecto de los bienes y servicios que se encuentran a su disposición en el mercado, con la finalidad de poder realizar una elección eficiente. Ahora, los Consumidores y usuarios modernos están cada vez más inclinados a elegir bienes y servicios ofrecidos por empresas que asumen compromisos de responsabilidad social. Entre las certificaciones, que en muchos casos llegan a constituirse en marcas, que ofrecen in- frustrados con las limitaciones de la utilidad de

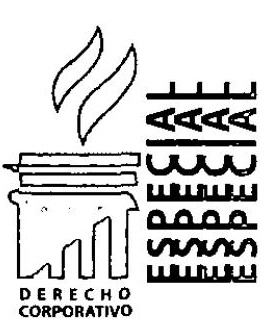

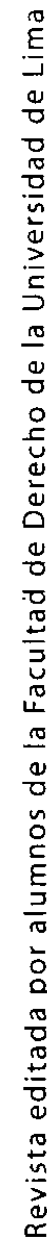

25 DAVID, Fred R, Conceptos de Administración Estratégica, Quinta Edición, Prentice Hall, México, p. 91.

26 ROWE, Alan J. et al, Strategic Management. A methodological approach, Addison-Wesley Publishing, New York, Company, 1994, p. 79.

27 GHARAJEDAGHI, Jamshid, Op. Cit., p. 172.

28 SCHWALB, María Matilde y MALCA, Oscar, Responsabilidad Social: fundamentos para la competitividad empresarial y el desarrollo sostenible, Fondo Editorial de la Universidad del Pacífico, CIUP, Yanacocha, Asociación Los Andes de Cajamarca, Lima, 2008, p. 33 y ss. 
formación y seguridad al consumidor, Schwalb y Malca, en su obra antes citada, destacan las siguientes:

(i) BASC (Bussines Antismugling Coalition): creada para prevenir embarques internacionales que permitan el narcotráfico y el terrorismo;

(ii) INFOAM (International Federation of Organic Agriculture Movements): que certifican sistemas o procesos que respetan las exigencias y capacidades naturales de las plantas, los animales y el paisaje;

(iii) FSC (Forest Stewardship Council): impulsado por el Fondo Mundial para la vida Salvaje para el buen manejo forestal;

(iv) ISO 14000: y en especial la norma técnica 14020 referida a etiquetado ambiental, difundida por la Organización Internacional para la Estandarización;

(v) FAIRTRADE: relativa al denominado "comercio justo" como alternativa al convencional;

(vi) MARINE STEWARDSHIP COUNCIL: que fomenta la pesca sostenible;

(vii) BIRD FRIENDLY: marca del Smithsonian Migratory Bird Center que sirve como referente a los consumidores que inclinan sus preferencias a la biodiversidad y preservación de las aves;

(viii)ECO-OK: sello creado por la Rainforest Alliance para certificar los productos de la agricultura conservacionista; $y$

(ix) PPMA: creada por la Organización Mundial del Comercio, que en realidad es un programa de Productos Preferibles para el Medio Ambiente.

Por consiguiente, el consumidor ha mostrado una serie de cambios dirigidos hacia una mayor consciencia de aspectos vinculados con la responsabilidad social. Esto ha determinado que las empresas modifiquen su propia concepción y actividad hacia una inclusión de la responsabi-

Sin embargo lo dicho hasta este momento, aún no explica de manera contundente cómo es que la responsabilidad social se inserta en la empresa de modo natural. Tenemos que ir más allá en el análisis para tratar el concepto de lucro tan importante para las empresas y su compatibilidad con la responsabilidad social.

\section{LA PERSONA JURÍDICA Y EL CONCEPTO DE LUCRO}

De acuerdo a una visión finalista, el lucro es entendido como la maximización en la obtención de beneficios con el objeto de repartirlos entre los propietarios de los capitales o los elementos productivos materia de la inversión. Esta noción que ha sido central en la organización de las personas jurídicas y en el desarrollo del mercantilismo moderno, sufre un quiebre cuando las necesidades sociales, la motivación altruista y solidaria comienzan a ganar terreno en el campo de la economía y buscan entre las formas societarias que contempla la ley, la modalidad asociativa y personalidad jurídica que mejor responda a sus intenciones.

En este punto entonces la gran pregunta es: ¿podemos lograr que las sociedades netamente mercantiles incorporen de alguna manera estos nuevos retos jurídicos? La respuesta es afirmativa. De hecho ya existen nuevas formas de organización empresarial que tratan de cubrir estos intereses como la denominada "empresa de inserción social" de la cual hablaremos más adelante. Pero el objetivo del presente artículo es ir más allá, y preguntarse sobre si las formas netamente societarias, y en especial, la sociedad anónima, pueden recoger dichos intereses e incorporarlos a su estructura orgánica o por decirlo de otra forma, si pueden existir Sociedades Anónimas de Responsabilidad Social, con siglas que las identifiquen y diferencien del resto, como podría ser la sigla "S.A. de R.S.". Esto reto casi "quirúrgico", supone abrir esa estructura orgánica de la persona jurídica tradicionalmente egoísta, para instalar en ella un corazón, o en otras palabras, dotarlas del otro gran sentimiento que impulsa al hombre: el solidario o altruista.

Conceptualmente no existe contradicción entre la responsabilidad social y el lucro, ya que una empresa responsable socialmente no es aquella que renuncia a los beneficios económicos. 
Es más, aun desde la concepción tradicional, la responsabilidad social de las empresas es importante por lo menos en dos sentidos: (i) incrementa el valor agregado de las empresas habida cuenta los cambios dados a causa de un consumidor más preocupado por su entorno, y (ii) pueden coexistir responsabilidad y lucro en un equilibrio que optimice el valor tanto en términos sociales como económicos.

En consecuencia, consideramos que la responsabilidad social es el elemento faltante necesario que corresponde a una concepción actual, moderna e integral de empresa, en armonía con sus elementos internos (i.e. lucro) como externos (i.e. consumidor).

Pero, ¿cuáles son los alcances que debe tener esta responsabilidad social de la empresa? ¿Hasta dónde nos permite llegar sus fundamentos? Esta importante cuestión la desarrollamos en el numeral siguiente.

\section{VIII.EL FUNDAMENTO DE LA RESPONSA- BILIDAD JURÍDICA DE LAS PERSONAS JURÍDICAS}

Tradicionalmente, la responsabilidad de las sociedades anónimas se ha explicado sobre la base de los siguientes elementos:

1. La agencia, que es el caso en el que se crea un mecanismo de gestión en el que el interesado (principal) no tiene la decisión, sino que se lo ha confiado a otra persona (agente):

2. La responsabilidad vicaria, es decir la responsabilidad por los dependientes; $y$

3. La identificación, es decir, que los directivos de una empresa no son extremidades de la sociedad anónima, sino que son quienes toman las decisiones, por ende se les identifica con la corporación.

Sin embargo para el caso de las sociedades anónimas, se da una característica especial que no se verifica para el caso de los individuos, a saber: la opacidad. "La opacidad de las grandes sociedades anónimas hace difícil identificar al individuo cuya acción o inconducta legal pueda ser atribuida a la sociedad a fin de poderlo valorar desde el entendimiento tradicional de las reglas de atribución. A este problema también se la llama 'el problema de las manos múltiples"'.29

En este orden de ideas, en la sociedad anónima, si bien se comparten algunos de los fundamentos de la responsabilidad de los individuos, no debe dejarse de lado que los costos de individualizar al autor de un hecho son especialmente altos cuando se trata de empresas grandes, por lo que no es razonable dejar sin protección a la víctima en razón de dicho obstáculo, sino que debe optarse por la atribución de responsabilidad a cargo de la sociedad anónima.

Para mitigar los alcances de esta opacidad la jurisprudencia comenzó a generar mecanismos como el descorrer el velo de la persona jurídica y la legislación aceptó en ciertos sectores el llamado principio de realidad. En este mismo devenir, aceptar los postulados de la responsabilidad social como modelo capaz de afectar el patrimonio de la persona jurídica, no es un despropósito ni desnaturaliza esta institución. Sin embargo, somos de la opinión que el problema debe ser resuelto en el ámbito societario, precisamente en uno de sus elementos esenciales: "El Objeto social".

\section{EL ORIGEN DE LA RESPONSABILIDAD SOCIAL DE LAS PERSONAS JURIDICAS Y EL OBJETO SOCIAL DE LAS SOCIEDADES ANÓNIMAS}

Para la mayoría de los autores, el verdadero origen de la Responsabilidad Social surge del Deterioro del Ambiente a causa de una actividad empresarial despreocupada. Si bien hoy en dia este punto está claro para todos, recordar algunas cifras y estadísticas no está de más. Así, siguiendo en el análisis a la Red de Responsabilidad Social ${ }^{30}$, tenemos que

29 CANE, Meter, Op. Cit., p. 159.

30 La Red de Responsabilidad Social; Calidad con Responsabilidad Social, noviembre de 2006. En: http//www.comunidadandina.org/

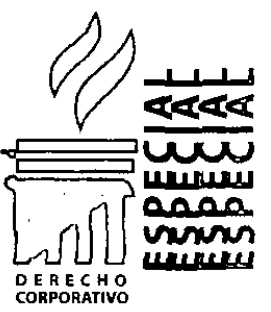

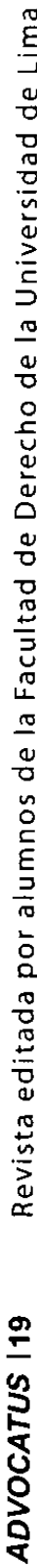


"el $50 \%$ de bosques y humedales han desaparecido en los últimos 100 años, correspondiendo a Latino América y Caribe la 2 da más alta tasa de deforestación; respirar en Calcuta, México y Teherán equivale a fumar 2 cajetillas de cigarrillos; en los últimos 50 años, las emisiones de carbono se han cuadriplicado, deshielo, aumento de los niveles del mar, aumento entre 1.5 a 5.8 grados $C$, etc. Generando el calentamiento global".

Desde una perspectiva sociopolítica, y siguiendo la misma fuente una segunda causa la encontramos en las inmensas diferencias e injusticias que aun subsisten en el sistema social. Así se resalta que 1,300 millones de personas viven en absoluta pobreza en el mundo, el $50 \%$ de la pobres del mundo vive con igual/menos de US\$2/día, 358 billonarios tienen tanta riqueza o más que el $45 \%$ de la población mundial; el consumo de un niño de un País desarrollado, equivale a lo que 40 niños de Países en desarrollo consumen.

Finalmente, este enfoque sociopolítico encuentra una tercera causa en la liamada crisis de las instituciones. En efecto, en América Latina: el $78 \%$ de la población tiene ninguna o muy poca confianza en los partidos políticos, el $65 \%$ en el Congreso y el $62 \%$ en el Poder Judicial. En Latinoamérica existen 189 millones de pobres, de los cuales el $18 \%$ están en extrema pobreza: la inversión de armas llega a más de un 1 billón de dólares, mientras que la ayuda a los pobres a 79 millones de dólares; o peor aun los países desarrollados gastan 12 veces más en armas, de lo que ayudan a los países en el mundo. Es decir, por cada 100 dólares de industria de armas los pobres en el planeta reciben $\$ 7.90$ y a pesar de ello la mitad de las exportaciones de armas van destinas a los países en desarrollo; el $35 \%$ de los niños de Oriente trabajan, el $40 \%$ de los profesionales no trabajan en lo que han estudiado.

Otro enfoque que llamaremos socioeconómico, ve en las políticas de gestión económica los trabajo $3 / 2003$, p. 7. verdaderos origenes de la responsabilidad social corporativa. Primero con la aparición de los Fondos Éticos en los años cincuenta creados por grupos religiosos, especialmente los cuáqueros y su decisión de no invertir en empresas cuyas actividades generan daños sociales, como la industria del alcohol y el tabaco. Destacan como segunda causa a las crisis bursátiles que siempre dan lugar a la necesidad de pensar en nuevos enfoques de desarrollo y gestión corporativa. Por ultimo, ven el surgimiento de las organizaciones no gubernamentales, ONGs, como un eficiente vehículo para el control de las externalidades privadas, que sin embargo no son asumidas por las empresas ni por el Estado.

Según el Documento de Trabajo de La Fuente $y \operatorname{otros}^{31}$;

"elenfoque Responsabilidad Social Corporativa de la gestión empresarial supone un nuevo modelo de gobierno de las externalidades empresariales en lo económico, social y medioambiental. Cabría decir que la atención pública respecto de los impactos sobre la sociedady el medio ambiente de las empresas adquiere un carácter universal en la segunda mitad de los años ochenta, como consecuencia de casos como los de Bophal o Exxon Valdez. Más recientemente, en la década de los noventa, el escrutinio se extiende a lo social, siendo paradigmáticos, por su impacto social los casos de Nike, y la fabricación de balones en Indonesia; Shell y su connivencia con el régimen dictatorial de Nigeria; o incluso Monsanto y su terquedad en la producción de organismos modificados genéticamente. La novedad aportada por el concepto RSC radica en que las demandas sociales de prácticas empresariales RSC no son intermediadas por el Estado y que, en una buena parte de las ocasiones, se articulan a través de los mercados de producto, consumo responsable; de capitales, inversión socialmente responsable (ISR) o Inversión RSC; o a través de otros activismos no intervenidos por los Estados".

31 LAFUENTE, Alberto; VIÑUALES, Victor y otros, Responsabilidad Social Corporativa y Politicas Públicas, Documento de 
En nuestra opinión, muchas empresas no están interesadas en las actividades e inversiones que conllevan la responsabilidad social y sus ejecutivos se escudan en el argumento"porque su objeto social no se los permite". Recordemos que el artículo 11 de nuestra Ley General de Sociedades señala:"La sociedad circunscribe sus actividades a aquellos negocios uoperaciones lícitos cuya descripción detallada constituye su objeto social. Se entienden incluidos en el objeto social los actos relacionados con el mismo que coadyuven a la realización de sus fines, aunque no estén expresamente indicados en el pacto social o en el estatuto".

La sociedad no puede tener por objeto desarroIlar actividades que la ley atribuye con carácter exclusivo a otras entidades o personas.

De esta manera, el carácter restrictivo del objeto social puede constituirse en un argumento no solo para justificar la evasión de responsabilidades sociales sino hasta para imputar responsabilidades jurídicas en quienes pretendan desarrollarlas en nombre de la empresa.

\section{X. ¿QUÉ ES RESPONSABILIDAD SOCIAL?}

Revisemos algunas de las definiciones más comunes, dadas por instituciones involucradas en políticas de Responsabilidad Social. Según la Red de Responsabilidad Social ${ }^{32}$, es una filosofía que tiene como pilares fundamentales, valores éticos y morales y cuya principal incidencia se manifiestan en nuestros actos y de qué manera estos pueden afectar o dañar a otra persona o a un determinado entorno social.

Para la Organización DERES de Uruguay "Es una visión de negocios que integra en la gestión empresarial y en la forma armónica el respeto por los valores éticos, las personas, la comunidad y medio ambiente".

Para el Instituto Ethos "La responsabilidad social es una forma de gestión definida por la relación ética y transparente de la empresa con todos los públicos con los cuales se relaciona y por el establecimiento de metas empresariales compatibles con el desarrollo sustentable de la sociedad, preservando recursos ambientales y culturales para las futuras generaciones, respetando la diversidad y promoviendo la reducción de las desigualdades sociales".

Para Perú XXI "es una forma ética de gestión que implica la inclusión de las expectativas de todos los grupos de interés (Accionistas/Inversionistas, Colaboradores y sus familias, Comunidad, Clientes, Proveedores, Medio Ambiente y Gobierno) alrededor de la empresa, para lograr el desarrollo sostenible. La Responsabilidad Social ayudará a la empresa a tomar conciencia de su rol en el desarrollo de nuestro país, reconociéndose como agente de cambio para mejorar la calidad de vida y la competitividad de su entorno".

La responsabilidad social de la empresa se presenta entonces como una decisión de naturaleza ética y aun fundamentalmente voluntaria, no impuesta, aunque exista cierta normatividad vigente en torno a la misma, pues no nace de la existencia de dicha normatividad o de obligaciones legales, ni menos aún se reduce a ella. Nace de las necesidades humanas, de la relación del hombre con el planeta y de las exigencias de un modelo económico y social sostenible en el tiempo, en donde todos los que nos vemos afectados tenemos intereses directos o indirectos, que tanto los Estados como las Corporaciones deben considerar en sus fines, actividades y estrategias de gestión. La responsabilidad social se aparta entonces del modelo egoísta que ve en el accionista el único centro de intereses a satisfacer e introduce un modelo solidario en donde otros intereses humanos, generales, sectoriales o grupales comienzan a jugar un rol preponderante.

Según Hernández $\mathrm{Gil}^{33}$, la responsabilidad social corporativa, por ejemplo, se ha convertido para

32 La Red de Responsabilidad Social, Op. Cit. En: http//www.comunidadandina.org/.

33 HERNANDEZ GIL, Antonio, Derecho y Responsabilidad Social. En: Ciberjure portal jurídico peruano, España, 04 de agosto de 2008. En: www.ciberjure.com.pe/index.phd, Portal jurídico.

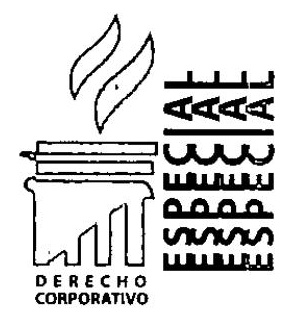

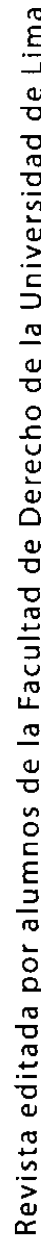

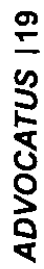


las empresas en una exigencia del mercado -de la sociedad por tanto-que les obliga a ir más allá de las obligaciones legalmente establecidas para atender a sus empleados, consumidores, socios o proveedores, y mejorar la situación de las comunidades donde se proyecta su acción.

Deben hacerlo con transparencia, de una forma regular que tiende a homogenizarse para facilitar la evaluación y la comparación; incluso frente al mandato básico para las sociedades mercantiles, de maximizar el beneficio de sus accionistas. La contradicción puede salvarse diciendo que la responsabilidad social corporativa es necesaria para atraer inversores y fidelizar clientes y empleados; pero la exigencia es anterior a la capacidad de aprovechar sus ventajas competitivas. Lo que está en juego es un concepto integrador y axiológico de "creación de valor" o "riqueza" (como en el artículo 128.1 de la Constitución) frente al "ánimo de lucro" a corto plazo en el puro sentido mercantil.

Sin embargo, ¿Son incompatibles egoísmo y altruismo? ¿Acaso no coexisten estos sentimientos ambivalentes en el ser humano, en la persona natural? Y si pueden coexistir en la persona natural, entonces por qué no pueden coexistir en la jurídica. A nuestro modo de ver, ánimo de lucro y de solidaridad pueden perfectamente coexistir si el objeto social así lo reconoce y acepta, en cuyo caso la responsabilidad dejaría de ser una función meramente voluntaria para integrarse a la visión y misión de la empresa y adquirir la categoría de responsabilidad jurídica.

\section{DE LOS "SHAREHOLDERS" A LOS "STAKE- HOLDERS"}

En un Documento de Trabajo de 2003, titulado "Responsabilidad Social Corporativa y Políticas Públicas" ${ }^{34}$ se señala:

"En cierta medida se entiende que la filosofia RSC (Responsabilidad Social Corporativa) es contrapuesta a la filosofía de creación de valor para el shareholder, preconizada por Friedman, como fin último de la actividad empresarial. Esta concepción de creación de valor para el accionista es reduccionista en comparación con la filosofía que subyace al concepto RSC (stakeholdervalue), que entiende que la empresa es una organización llamada a jugar un papel activo en la configuración de la sociedad, cuya misión debería ser la creación de valor para stakeholders más allá del accionista. Esta filosofía va más allá: la creación de valor para los distintos stakeholders redunda en una mayor creación de valor para el accionista".

La divergencia entre ambos enfoques queda puesta de manifiesto en el documento Business partnering frontiers: Social purpose alliances, del que es autor James E. Austin. De un lado, el "enfoque shareholder", o de creación de valor para el accionista, argumenta que la única responsabilidad de las empresas es conducir sus actividades, dentro de la legalidad, con el fin exclusivo de maximizar el valor revertido a sus accionistas. Esa es su única responsabilidad y, además, la adopción de enfoques más amplios distrae la atención de los gestores y acaba dañando el valor creado para el accionista.

De otro, el "enfoque stakeholder"viene a apoyar, utilizando como argumento el Business case (razón de ser empresarial) de la RSC, una concepción de la actividad empresarial a través de la cual las empresas crean valor para el accionista a través del adecuado gobierno de las relaciones con el conjunto de stakeholders, lo que no discute la primacía del capital como input director de la empresa, pero pone en evidencia el carácter abierto a la sociedad de la institución empresarial. El enfoque stakeholder ha cristalizado en la cultura corporativa de la RSC. Esta forma de entender la empresa "se refiere esencialmente a la evidencia de que en el largo plazo los resultados empresariales mejoran si se mantienen relaciones no oportunistas con los diferentes grupos de interés que concurren en la actividad

34 LAFUENTE, Alberto; VIÑUALES, Victor; PUEYO, Ramón y LLARÍA, Jesús. En: www.ecodes.org/documentosecodes/ ecodes_fa_RSC_politicas_públicas.pdf. 


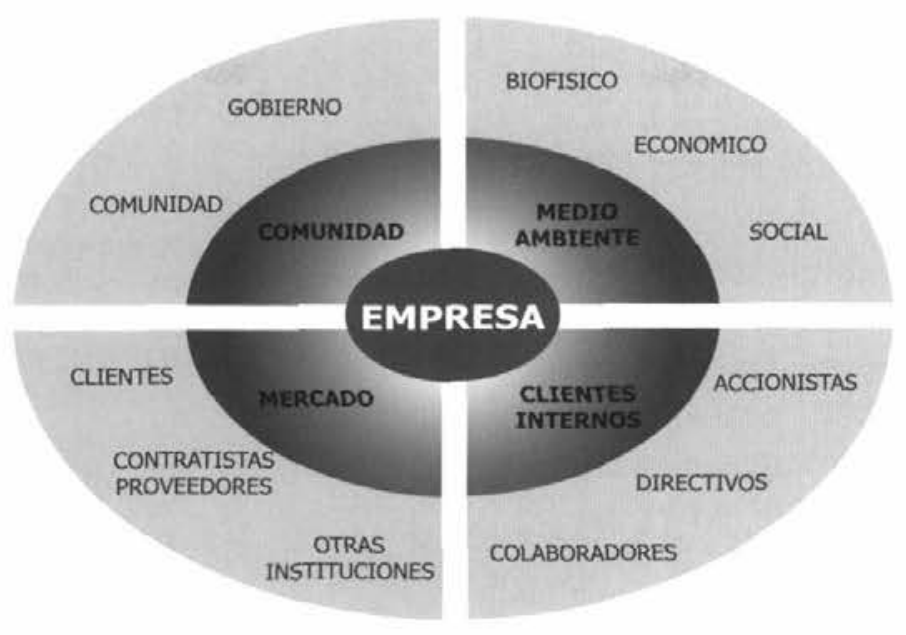

empresarial: empleados, clientes, proveedores, y comunidades sociales donde se opera".

Resulta interesante mostrar un mapa en donde se aprecien las categorías que conforman los stakeholders a efectos de apreciar los alcances de la responsabilidad social.

En consecuencia, y en respuesta a la pregunta sobre los alcances de la responsabilidad social de la empresa, debe señalarse que esta responsabilidad alcanza a todos los elementos integrantes de los stakeholders.

\section{INCLUSIÓN EMPRESARIAL Y CULTURA CORPORATIVA}

Como se explicó anteriormente, además de la responsabilidad social, el otro concepto clave para entender la problemática actual de las empresas es el de inclusión. Esta palabra cada vez se escucha con más frecuencia en ámbitos como la educación, la psicología, la política, la cultura, las ciencias sociales, las profesiones y últimamente en la esfera empresarial. Lo interesante de lo ocurrido con la inclusión aplicada a la esfera empresarial es que ha dado lugar a una nueva forma de organización profesional, como son las llamadas Empresas de Inserción Social, también conocidas como Empresas de Inserción Laboral o Socio-Laboral, para aludir a las características esenciales de este tipo de empresas: su fundamento es el principio de solidaridad, y su objetivo, la inserción social de ciertas personas con particulares dificultades, previa su inserción laboral.

Siguiendo a Maria Isabel Álvarez Vega, Profesora de Derecho Mercantil de la Universidad de Oviedo, interesa destacar que la Empresa de Inserción Social es una nueva forma de organización social y económica que se enmarca dentro de las estructuras de inserción por lo económico. Pretende ser una respuesta eficaz, por parte de la Economía Social a la crisis del desempleo, abordada desde una vertiente empresarial. Es un tipo de experiencia que al combinar la lógica empresarial con la de la inserción social, está demostrando su éxito en ciertos países como Italia, Bélgica o Francia y que en España en un corto plazo gozará de un marco jurídico legal específico.

La idea esencial de la Empresa de Inserción Social es combinar la lógica empresarial con la lógica de la inserción social. Para atender a estos fines las Empresas de Inserción Social destinan una parte de sus puestos de trabajo a personas en inserción, promoviendo la integración sociolaboral de colectivos marginados.

Según la referida autora estas empresas plantean ciertos interrogantes cuando las formas jurídicas de los promotores son las propias de la Economía Social, ya que surge conflicto entre la naturaleza propia de la fórmula normalmente 
elegida y su constitución como empresarios (supuesto en que la organización promotora ostente la titularidad directa de la empresa) o como socios en las EIS (Empresas de Inserción Social). Esta controversia enfrenta dos conceptos aparentemente antagónicos. Por una parte, la ausencia de ánimo de lucro (en su acepción tradicional) y la realización de fines de interés general son consustanciales a la fórmula jurídica adoptada por los promotores; por otra, la realización de actividades empresariales persiguiendo en último término la obtención de una rentabilidad o ganancia. Desde el punto de vista constitucional, agrega, aquella contradicción supone el conflicto entre distintos principios contenidos en la Carta Magna: el del derecho de Fundación (artículo $34 \mathrm{CE}$ ), la función social de la propiedad (artículo 33 CE) y el de la libertad de empresa (artículo $38 \mathrm{CE}$ ). Este conflicto se resuelve compaginando estos principios constitucionales en atención a una "función social" del empresario y de la empresa. ${ }^{35}$

\section{LAS ASOCIACIONES PÚBLICO-PRIVADAS Y EL DESARROLLO DE POLÍTICAS PÚBLI- CAS DE RESPONSABILIDAD SOCIAL}

En nuestro país, desde hace algunas décadas se ha empleado un nuevo modelo económico a efectos de cubrir las necesidades sociales tanto en servicios como en infraestructura. Este esquema de la Asociación Público-Privada es un concepto que involucra a los sectores público y privado, a fin de colaborar de forma asociada para proveer servicios e infraestructura. La finalidad es crear el activo y luego brindar servicios a un sector de usuarios, a cambio de pagos adecuados a los niveles del servicio brindado. A través de las Asociaciones Público-Privadas, se puede realizar lo siguiente:

(i) La construcción, instalación o transformación de obras, equipos, sistemas, y productos o bienes complejos, asi como su mantenimiento, actualización o renovación, su explotación o su gestión.

(ii) La gestión integral del mantenimiento de instalaciones complejas.

(iii)La fabricación de bienes y la prestación de servicios que incorporen tecnología específicamente desarrollada con el propósito de aportar soluciones más avanzadas y económicamente más ventajosas que las existentes en el mercado.

(iv)Otras prestaciones de servicios ligadas al desarrollo por la Administración del servicio público o actuación de interés general que le haya sido encomendado.

Sin perjuicio de otros ámbitos de actividad empresarial, el campo de colaboración PúblicoPrivada plantea la necesidad de reconocer que cuando la empresa privada interviene en este espacio público-privado sus actividades no se definen únicamente desde la perspectiva individual sino también desde la serie de intereses públicos directamente ligados a dichas actividades. Esto no debe interpretarse en el sentido de que el privado asume las funciones del Estado, puesto que la titularidad de la función y la potestad públicas son siempre del Estado. ${ }^{36}$ Es importante entender que en este ámbito especial, el privado deja cierto ámbito de libertad para estar al servicio de la sociedad, y el Estado retrocede precisamente para que intervenga el privado, o dicho de otra manera, la intervención del privado en el ámbito de los bienes y servicios públicos obedece a intereses privados y públicos, e incluso a intereses de responsabilidad e inclusión social. Asi, las Asociaciones Público-Privadas suelen tomar en cuenta políticas sobre responsabilidad social, especialmente referidas a:

- Igualdad de trato.

- No discriminación.

35 Las Empresas de Inserción Social como nueva forma de organización empresarial. Especial referencia a su régimen jurídico.

36 Puede decirse que la intervención en vía de colaboración del privado en el ejercicio de las funciones públicas no puede afectar el contenido esencial de las mismas (núcleo duro), en caso contrario se desnaturalizaría el mismo concepto de Estado. 
- Buen gobierno corporativo.

Proporcionalidad.

- Libre competencia, en dos niveles: (i) competencia de entrada, (ii) competencia de salida. ${ }^{37}$

- Principios de continuidad e integridad.

- Trabajo digno y humano.

- Preservación del ambiente.

- Desarrollo sostenible. ${ }^{38}$

En consecuencia, la responsabilidad social resulta ser un elemento necesario y definitorio de la actividad del privado en el ámbito de las asociaciones publico-privadas, por el gran impacto de las actividades que realiza sobre la sociedad. Así, sería un lugar ideal para el desarrollo de las Sociedades Anónimas de Responsabilidad Social cuya creación proponemos, pues es inmejorable para efectos de armonizar los intereses individuales y sociales, así como los intereses públicos y privados. ${ }^{39}$

\section{CONCLUSIÓN: LA NECESIDAD DE CREAR UNA SOCIEDAD ANÓNIMA DE RESPON- SABILIDAD SOCIAL}

Una de las preguntas esenciales de este trabajo es si la persona jurídica puede cumplir el rol social y de inclusión que se le reclama. Nuestra respuesta es afirmativa y nuestra propuesta es la creación de una nueva forma de sociedad anónima: la Sociedad Anónima de Responsabilidad Social, con ello se busca armonizar los elementos internos (i.e. lucro) y externos (i.e. consumidor) de la empresa, desde el punto de vista, tanto de los accionistas (Shareholders) como de los "stakeholders".

Las Sociedades Anónimas de Responsabilidad Social pueden encontrar en el ámbito especial de las Asociaciones Público-Privadas un lugar ideal para su desarrollo, aunque no sea el único por cierto.

37 Existen casos en que la competencia es destructiva. No genera beneficio social. Sin embargo, la libre competencia debe expresarse en la entrada (igualdad de condiciones legales entre los postores), y en la salida (cláusula de sustitución en caso que el adjudicatario no sea eficiente). Ver: SHARKEY, William W., The theory of natural monopoly, Cambridge University Press, Cambridge, 1982, p. 54 y ss. Este es el caso de las concesiones, en las que la eficiencia no requiere de una gran cantidad de agentes ofertantes, sino de uno o unos cuantos.

38 Para la Comisión Mundial sobre el Medio Ambiente y Desarrollo de las Naciones Unidas (1987): "El desarrollo sostenible: proceso en donde se asegura la satisfacción de las necesidades humanas del presente sin que se ponga en peligro la capacidad de las generaciones futuras para atender sus propias necesidades y que, por ende, involucre la utilización de recursos, la dirección de las inversiones y la orientación de los cambios tecnológicos e institucionales que acrecienten el potencial actual y futuro de los recursos naturales en aras de atender las necesidades y aspiraciones humanas".

Sobre la relación entre desarrollo sostenible y responsabilidad social nuestro Tribunal Constitucional a señalado: "El desarrollo sostenible o sustentable requiere de la responsabilidad social: ello implica la generación de actitudes y comportamientos de los agentes económicos y el establecimiento de politicas de promoción y el desarrollo de actividades que, en función del aprovechamiento o uso de los bienes ambientales, procuren el bien común y el bienestar general". (Ver: Sentencia del Tribunal Constitucional No. 0048-2004-PI/TC, del 1 de abril de 2005).

39 Sin embargo, queda claro que la sociedad anónima de responsabilidad social no solo tiene como ámbito de actuación el de las Asociaciones Público-Privadas, sino cualquier otro sector, habida cuenta que la empresa siempre tendrá en frente a determinados stakeholders a quienes responder por sus actos. 